\title{
MINORÍAS SEXUALES, DE GÉNERO Y EDUCACIÓN: DEMANDAS Y LUCHAS LGBTI EN EL CONTEXTO BRASILEÑO
}

\section{SEXUAL, GENDER AND EDUCATION MINORITIES: LGBTI DEMANDS AND STRUGGLES IN THE BRAZILIAN CONTEXT}

\author{
Luiz Paulo Ribeiro(*). Universidade Federal de Minas Gerais - Brasil \\ luizribeiro@live.com \\ Mariana Esteves da Costa(*). Universidade Federal de Minas Gerais - Brasil \\ mariana.esteves@live.com \\ Isabella Campos Freitas D'Avila(*). Universidade Federal de Minas Gerais - Brasil \\ isabellacf.davila@gmail.com
}

\begin{abstract}
Resumo: A Educação é um direito de todos e dever da escola, da família e da sociedade, entretanto nem sempre se mostra democrática quando se trata das minorias sexuais e de gênero. No Brasil, as violências e estigmatizações de estudantes LGBTI ocasionam baixa escolaridade e muitos outros desdobramentos sociais. Pensando nisso, a população LGBTI, através de movimentação política e social, tem buscado garantir o direito de acesso e permanência nas instituições de ensino. Assim, este trabalho tem como objetivo explicitar como as ações do movimento LGBTI têm contribuído historicamente para as transformações na educação. Consideramos que as mudanças na Educação acontecem, entre outros fatores, por meio da influência desses sujeitos, e por aqueles que entendem a importância do respeito à diversidade na Escola, que se mostra como um espaço hostil marcado, por vezes, pela cisheteronormatividade. Por meio do conceito de minorias ativas, buscamos compreender como os sujeitos LGBTI contrapõem-se às regras e normas sociais impostas pela maioria e influenciam as transformações sociais. Entendemos que a reprodução de regras e padrões de comportamento no ambiente educacional tendenciam uma lógica antidemocrática, na qual os educandos não são inteiramente respeitados quando apresentam identidades e sexualidades consideradas dissidentes.
\end{abstract}

Palavras-chave Minorias sexuais e de gênero; Educação; Educação democrática; Brasil; Gênero.

Resumen: La Educación es un derecho de todos y deber de la escuela, de la familia y de la sociedad sin embargo no siempre se muestra democrática cuando se trata de las minorías sexuales y de género. En Brasil las violencias y estigmatizaciones de estudiantes LGBTI ocasionan baja escolaridad y muchos otros desdoblamientos sociales. Pensando en ello, la población LGBTI, a través de movimientos políticos y sociales, ha procurado garantizar el derecho de acceso y permanencia en las escuelas. Así, este trabajo tiene como objetivo explicitar cómo las acciones del movimiento LGBTI han contribuido históricamente a las transformaciones en la educación. Consideramos que los cambios en la Educación suceden, entre otras, por medio de la influencia de esos sujetos, y por aquellos que entienden la importancia del respeto a la diversidad en las instituciones educativas, que se muestran como espacio hostil marcado, a veces, por la cisheteronormatividad. Por medio del concepto de minorías activas, buscamos comprender cómo los sujetos LGBTI se contraponen a las reglas y normas sociales impuestas por la mayoría e influyen en las transformaciones sociales. Entendemos que la reproducción de normas y patrones de comportamiento en el ambiente 
educativo tiende a una lógica antidemocrática, en la que los alumnos no son plenamente respetados cuando presentan identidades y sexualidades consideradas disidentes.

Palabras clave: Minorías sexuales y de género; Educación; Educación democrática; Brasil; Género.

\begin{abstract}
Education is a right of all and a duty of school, family and society, however it is not always democratic when it comes to sexual and gender minorities. In Brazil, the violence and stigmatization of LGBTI students cause low schooling and many other social developments. Thinking about it, the LGBTI population has sought to guarantee the right of access and permanence in educational institutions through political and social movement. Thus, this work aims to clarify how the actions of the LGBTI movement has been contributing historically to the transformations in education. We consider that changes in Education happen, among others, through the influence of these subjects, and by those who understand the importance of respect for diversity in School, which shows itself as a hostile space marked, sometimes, by cisheteronormativity. Through the concept of active minorities, we seek to understand how LGBTI individuals oppose the social rules and norms imposed by the majority and influence social transformations. We understand that the reproduction of rules and patterns of behavior in the educational environment tends to an anti-democratic logic, in which the students are not fully respected when they present identities and sexualities considered dissident.
\end{abstract}

Keywords Sexual and gender minorities; Education; Democratic education; Brazil; Gender.

\title{
1. Introdução
}

O direito à Educação faz parte da Declaração Universal dos Direitos Humanos, estabelecida pela ONU em 1948, através do artigo XXVI, que diz que "todo ser humano tem direito à instrução". No Brasil, depois da vivência de um processo ditatorial (19641985), com as lutas populares, foi possível garantir esse direito no âmbito legal brasileiro. Através da Constituição Federal de 1988-CF/88, o direito à Educação passou a ser dever do Estado, com vistas "ao pleno desenvolvimento da pessoa, seu preparo para o exercício da cidadania e sua qualificação para o trabalho" (Brasil, 1988).

Dessa forma, compreendendo que a educação é um direito de todos, ressaltamos o que a CF/88 traz em seu Artigo 206, inciso I. Consta no referido artigo que deverá haver "igualdade de condições para o acesso e permanência na escola". Entretanto, não é difícil verificar que a realidade da Educação no Brasil ainda não se mostra eficaz quanto ao acesso e permanência de alguns grupos que encontram diferentes entraves para isso. Em 2010, constatou-se que 700 mil crianças de 7 a 14 anos não estavam na escola (Monroe, 2011). Além disso, a partir de um projeto de organização civil chamado "Todos pela Educação", que buscou elaborar diagnósticos com o objetivo de melhorar a educação do país, estimou-se que dentre 3,2 milhões de jovens de 19 anos no Brasil, apenas $63,5 \%$ (2 milhões) concluíram o Ensino Médio, 1,2 milhões não finalizaram nem a Educação Básica, sendo que $55 \%$ destes pararam os estudos ainda no Ensino Fundamental. A pesquisa também aponta dados relacionados às desigualdades, evidenciando que "adolescentes negros e moradores das áreas rurais do país 
apresentam taxas de conclusão mais baixas que as de seus pares brancos e de regiões urbanas em todas as etapas da Educação Básica" (Todos pela Educação, 2018, p. 2).

As desigualdades estendem-se a outros grupos, como os/as estudantes lésbicas, gays, bissexuais, travestis, transexuais e intersexo $\left(\mathrm{LGBTI}^{1}\right)$. De acordo com a Pesquisa Nacional sobre o Ambiente Educacional no Brasil (2016), 73\% dos estudantes entrevistados sofreram agressões verbais devido a sua orientação sexual e $55 \%$ já escutaram comentários negativos relacionados às pessoas trans (Associação Brasileira de Gays, Lésbicas, Bissexuais, Travestis, Transexuais e Intersexos, 2016). Ainda nesse sentido, em uma pesquisa feita com pessoas LGBT que vivem no Quebec - Canadá, $32,1 \%$ dos estudantes LGBTI sentem medo com relação a sua segurança e $29,8 \%$ dos estudantes LGBT já experienciaram assédio, bullying e discriminação na escola (Blais, Philibert \& Chamberland, 2018). As relações que os estudantes desse grupo minoritário constroem com a escola influenciam na sua permanência e também na probabilidade da conclusão dos estudos. Essa ideia ganha força ao pensar que quando os estudantes encontram professores e funcionários que os acolhem, eles possuem maior probabilidade de se sentir pertencentes à instituição, menor probabilidade de faltar às aulas por insegurança e menor probabilidade de sentirem medo dentro da instituição por causa da sua orientação ou identidade de gênero² (Associação Brasileira de Gays, Lésbicas, Bissexuais, Travestis, Transexuais e Intersexos, 2016).

Visualizando esse contexto e verificando a educação como direito, parte-se do pressuposto de que a Educação e a Política andam lado a lado e devem abarcar ações coletivas, com base no respeito e diálogo, para que as decisões políticas contemplem a realidade dos sujeitos educandos (Freire, 1967 [2019]). Assim, torna-se necessário que exista um projeto político de Educação que atenda às demandas da sociedade contemporânea que é heterogênea, de maneira a tornar a discussão sobre diversidade algo presente na Escola. Isso porque acredita-se que a Educação é um veículo informativo e interventivo sobre as questões relacionadas à diversidade sexual e de gênero, pois uma educação ministrada com base em princípios democráticos contribui para uma sociedade democrática.

Resgata-se que a Educação no Brasil é regulamentada pela Lei de Diretrizes e Bases da Educação Nacional, Lei nº 9394/96, que estabelece a defesa do "pluralismo de ideias e respeito às concepções pedagógicas" (Art. $3^{\circ}, \mathrm{III}$ ). Sendo que os debates que permeiam gênero e sexualidade encontram-se principalmente nos Parâmetros Curriculares Nacionais (PCNs), que indicam que

\footnotetext{
${ }^{1}$ Existem variações da sigla para se referenciar as pessoas LGBTI, como LGBTQ+, porém, este trabalho tomará como regra a sigla incluindo o I, levando em conta a invisibilização que esse grupo de pessoas sofre.

${ }^{2}$ As porcentagens aumentam cerca de $20 \%$ quando o número de professores e colaboradores que acolhe os estudantes LGBT é maior do que 6 .
} 
[...] a sexualidade no espaço escolar não se inscreve apenas em portas de banheiros, muros e paredes. Ela "invade" a escola por meio das atitudes dos alunos em sala de aula e da convivência social entre eles. Por vezes a escola realiza o pedido, impossível de ser atendido, de que os alunos deixem sua sexualidade fora dela. (Brasil, 1999, p. 292)

Entretanto, apesar da legislação em apoio ao abarcamento das questões das minorias sociais, "no Brasil, o paradoxo máximo está em termos uma legislação que garanta igualdade para todos, mas esse mesmo Estado é omisso na formulação de estratégias para garantir o previsto na lei" (Bento, 2017, p. 55). Embora tenha sido feita a inclusão dessa temática nos currículos escolares, as discussões no entorno das sexualidades, homossexualidades, bissexualidades e demais identidades e expressões de gênero fica a cargo da escola, que pode abordá-los sob diferentes "pontos de vista, valores e crenças existentes na sociedade para auxiliar o aluno a construir um ponto de autorreferência por meio da reflexão" (Brasil, 1999, p. 299). A responsabilidade destinada à escola em discutir a diversidade não garante que a Educação seja de fato democrática, ou que vá garantir a não violência contra pessoas LGBTI, ou uma cultura pró-diversidade.

Por outro lado, o governo atual - eleito em 2018 e com perspectiva de se manter até 2022 - através de uma lógica conservadora e neoliberal (Gentili, 1996) tem se movimentado pela não discussão de gênero e diversidade sexual nas escolas, através, por exemplo, da PL 7180/14, conhecida como "Escola sem partido", que prevê a alteração no artigo $3^{\circ}$ da Diretrizes e Bases da Educação Nacional, Lei no 9.394 (Brasil, 1996), que propõe um ensino moral e religioso e que nega relevância da discussão de diversidade sexual e de gênero nas escolas. Isso abre brechas para a escola se tornar palco de desigualdades e violências que perpassam pelas questões de gênero e sexualidade, podendo vincular esses movimentos, com uma educação antidemocrática, que não vê possibilidade de diálogo e construção conjunta (Freire, 1967; Antunes \& Peroni, 2017). Dessa forma, abre-se espaço para as violências advindas do que Freire (1967) chama de antidiálogo, uma relação vertical entre os indivíduos, fortalecendo a acriticidade, caráter que dificulta a construção de uma democracia, e de

Uma educação que possibilitasse ao homem a discussão corajosa de sua problemática. De sua inserção nesta problemática. Que o advertisse dos perigos de seu tempo, para que, consciente deles, ganhasse a força e a coragem de lutar, ao invés de ser levado e arrastado à perdição de seu próprio "eu", submetido às prescrições alheias. Educação que o colocasse em diálogo constante com o outro. Que o predispusesse a constantes revisões. À análise crítica de seus "achados". A uma certa rebeldia, no sentido mais humano da expressão. Que o identificasse com métodos e processos científicos. (Freire, 1967, p. 90)

O movimento por um antidiálogo contribui para as violências que se passam dentro das escolas, em formato de intolerância pelas diferenças, corroborando para a 
construção de um relacionamento ruim dos estudantes com o ambiente escolar. Isso geralmente ocasiona desistência dos estudos, o que, nesse sentido, seria limitado tratar como evasão, sendo mais adequado o uso da palavra expulsão (Bento, 2011). Usar a palavra expulsão na lógica da educação atual faz sentido, ao se pensar que se vive em uma sociedade que possui normas sociais, padrões a serem seguidos que transformam alguns grupos em seres abjetos, que fogem do que é dado como normal. A escola, como instituição pertencente à sociedade, reproduz a lógica lida através das discussões da necropolítica, uma vez que constrói um imaginário social que hierarquiza e categoriza pessoas, sendo alguns grupos colocados neste lugar de objeto, definindo aqueles que são descartáveis e os que não são (Mbembe, 2016). Ao refletir sobre os problemas enfrentados pelos sujeitos LGBTI na escola, Bento (2017) aponta para o apagamento de tudo aquilo que se refere aos gêneros dissidentes dentro dela, tornando suas identidades apagadas, faz com que eles não assumam seu lugar de sujeitos de direitos naquele espaço, legitima a noção da necropolítica. Assim, os alunos e alunas LGBTI sofrem constantemente os esforços dos personagens escolares para sua saída ou para sua adequação na norma, existindo uma pedagogia da sexualidade (Louro, 2000).

A pedagogia da sexualidade refere-se ao entendimento de que a sexualidade é construída ao longo de sua vida e encontra-se não apenas no espaço pessoal, mas também no campo político e social. Tal construção pode acontecer de diferentes maneiras, dependendo das normas, regras e tabus que perpassam à educação do sujeito em um determinado tempo e espaço (Louro, 2000). Dentro dessa ideia, a Escola pratica uma pedagogia da sexualidade cisheterocentrada, ou seja, que não abarca os sujeitos LGBTI porque nas entrelinhas e nos seus discursos defende a heterossexualidade, a não liberdade afetivo-sexual, uma relação hierárquica entre o homem e a mulher e a aceitação compulsória dos corpos.

Ao retomar a CF/88 brasileira e a Declaração dos Direitos Humanos, entende-se que tal prática fere um direito constitucional e, por isso, necessita ser repensada e, assim, estabelecer meios para garantir uma educação democrática. Mas, para tal, é necessário o envolvimento de todos os atores da comunidade escolar: Professores, Educadores, Gestores, alunos, pais ou responsáveis e comunidade, em prol de uma Educação que atenda e reflita a diversidade presente na escola.

De acordo com Freire (1967 [2019]), a democracia não é somente uma forma política, antes disso ela é também uma maneira de vida que embarca uma consciência contingente, que só pode ser vivenciada por meio da reflexão crítica e do debate acerca dos problemas individuais de cada sujeito e dos problemas comuns: "Quanto mais crítico um grupo humano, tanto mais democrático, e permeável, em regra.Tanto mais democrático mais ligado às condições de suas circunstâncias" (p. 126).

Dessa forma, para Freire (1967 [2019]), o processo educativo deve ser um instrumento democrático e, para isso, a educação deve estar em sintonia com a realidade dos educandos. Uma educação democrática deve envolver as diferentes 
circunstâncias presentes na escola, de modo que se o espaço escolar se apresente por meio de sujeitos diversos. No que se refere à identidade e sexualidade, a educação deve debruçar-se sobre suas experiências, desejos e visões de mundo para que possam ser efetivamente democráticas. As pautas e lutas da população LGBTI apontam um caminho em direção a uma escola para todos, que respeita a individualidade e trabalha com a diversidade. Assim, este ensaio tem como objetivo reconhecer como as lutas e pautas das minorias sexuais (LGBTI) no Brasil têm contribuído para a construção de uma educação que seja para todos os sujeitos, que seja democrática.

\section{Minorias e minorias ativas}

Um sistema hegemônico produz padrões e normas, dita regras no que se refere a comportamento, classe, raça, sexualidade, entre outros. Tenta organizar e normatizar comportamentos e subjetividades, impondo aquilo que é considerado normal ou não, aquilo que deve ser feito, ou não, e dividindo aqueles que são considerados importantes pra sociedade daqueles que não são. Essa normatização exclui diferentes grupos sociais, que não são representados politicamente e socialmente pelo sistema, tais grupos podem ser chamados de minorias.

O conceito de minorias não está relacionado à quantidade numérica, e sim, a grupos que se encontram excluídos dos padrões hegemônicos. Esses grupos podem representar uma considerável parcela da população, como, por exemplo, as mulheres que se encontram em desvantagem em setores da sociedade quando comparadas aos homens. Outros fatores que podem ser citados como minorias no contexto brasileiro são: a classe social, a raça/etnia, os portadores de necessidades especiais, a orientação sexual, entre outros. Uma minoria não é determinada por um grupo com um número definido ou idêntico entre si, mas sim pelo interesse coletivo de uma mudança social que coloca as minorias em um "lugar de transformação e passagem, assim como o autor de uma obra é um "lugar" móvel de linguagem" (Sodré, 2005, p. 3).

Dessa forma, as minorias são grupos que se encontram em lugares minoritários, contrários à lógica hegemônica e que buscam de forma ativa desfazer a vulnerabilidade social e legal em que se encontram. Social pela forma como são identificadas na sociedade e legal por uma fragilidade na construção de políticas públicas, por ser um grupo não institucionalizado (Sodré, 2005). Tal vulnerabilidade é constituída pelos grupos hegemônicos através de uma tentativa de enquadramento no padrão esperado, pelo normal constituído socialmente com apoio da igreja e do Estado. Isso se dá através da violência que, em seus diversos formatos, física ou simbolicamente, é concretizada pela via da discriminação, preconceito e rejeição, coloca os grupos minoritários à margem, negando tudo o que é diferente da norma ditada (Carmo, 2016).

De acordo com Moscovici (2011), "a maioria simboliza ao mesmo tempo a norma e a realidade, enquanto que a minoria representa a exceção, o anormal e a irrealidade"(p. 177). Os grupos que não se enquadram dentro dos padrões IQUAL. REVISTA DE GÉNERO E IGUALDAD, 2021, 4, 124-141 http://dx.doi.org/10.6018/iqual.440901 
anteriormente citados são colocados à margem da sociedade e não usufruem dos mesmos privilégios sociais, encontrando-se então em uma posição de desvantagem em relação ao grupo representado pelo sistema. Para Chaves (1971) "as minorias recebem, quase sempre, um tratamento discriminatório por parte da maioria" (p.149).

Assim, como acontece a exclusão de determinados grupos - por classe, gênero, sexualidade, raça, etc. - também acontece a reação desses grupos que lutam para serem representados e terem voz na sociedade. Os diferentes movimentos sociais que representam essas minorias são exemplos dessa reação. Por meio deles, ou outras ações políticas, os grupos minoritários buscam ser reconhecidos (vistos, serem considerados vivos), respeitados e terem seus direitos garantidos.

O reconhecimento das minorias é um fator fundamental na busca de uma sociedade democrática, uma vez que poderia permitir a esses grupos exercer suas próprias convicções, crenças, culturas, sem se preocupar em ser colocado à margem da sociedade ou até mesmo serem estigmatizados. O reconhecimento, portanto, deve atuar como essência para a diversidade social, pois só assim é que se promoverá uma sociedade mais justa e igualitária, por meio da valorização das diferenças existentes, evidenciando que todos são detentores de direitos e que são iguais não obstante as diferenças.

As lutas pelo reconhecimento não se desenvolvem somente no espaço político e social, mas se ampliam para o terreno cultural e individual. Nesse sentido, é necessário pensar que as minorias, justamente pela posição na qual se encontram submetidas, atravessam dificuldades para serem reconhecidas. Com isso, pode-se inferir que se lançar contra a ideia de uma maioria é se colocar diante de um confronto em uma posição desvantajosa socialmente. Sendo assim, as minorias, ao tentarem inovar, estão diante de um desafio muito maior do que aqueles que não vão contra as normas impostas pela maioria. Essas possuem o desejo de se reafirmarem e serem vistas da mesma forma que as demais, também procuram a aprovação social, seja daqueles que mais se aproximam de sua ideia, ou daqueles que a confrontam. Essa busca pela mudança está relacionada ao desejo de mudar a realidade dos demais e a sua conformidade com as normas impostas (Moscovici, 2011).

A partir dessa ideia, o conceito de Minorias Ativas entra em congruência com o exposto, compreendendo que é justamente aquelas que mesmo sem ou com poucas representações políticas e estigmas, lutam para romper com a lógica hegemônica. As minorias ativas movimentam a sociedade, são aquelas que, mesmo tendo consciência das dificuldades, são capazes de confrontar as normas em prol de uma mudança para todos, que questionam o mundo que lhes foi apresentado. E é a partir do questionamento que pode haver ruptura.

Muito especialmente a partir dos anos 1960, jovens, estudantes, negros, mulheres, as chamadas minorias sexuais e étnicas passaram a falar mais alto, 
denunciando sua inconformidade e seu desencanto, questionando teorias e conceitos, derrubando fórmulas, criando novas linguagens e construindo novas práticas sociais. (Louro, 2008, p. 20)

Por meio desse entendimento de que as minorias provocam mudanças, Moscovici (2011) mostra o quanto as minorias podem emitir influência sobre uma maioria, algo que contrapõe o modelo funcionalista que não coloca essa possibilidade nas discussões, visto que essa considera apenas a lógica da mudança social a partir da maioria. A teoria apresenta possibilidades de como a minoria pode influenciar a maioria e provocar transformações, embora a influência não seja um processo único e tampouco simples.

\section{Minorias sexuais e de gênero}

As minorias sexuais e de gênero, compostas por pessoas LGBTI e pelas mulheres, possuem uma longa trajetória na luta contra a lógica hegemônica cisheteronormativa e sexista, que afeta todos os indivíduos da sociedade, incluindo as pessoas que se enquadram dentro do grupo minoritário em questão. Ao dizer sobre as pessoas LGBTI, estas por vezes constroem uma visão negativa sobre si próprias, acreditando que possuem algum defeito, ou que são indignos de serem felizes (Igartua \& Montoro, 2015), sentimento construído a partir da compreensão de que ser cisgênero e heterossexual é o normal. Esse movimento contra hegemônico faz parte de uma busca pela igualdade de direitos, em um processo pela democracia, considerando o seu conceito como um "eterno problematizar que não possui fim, que sempre se bifurca e produz novas questões" (Rodrigues, 2010, p. 19). A abertura para problematização acerca da maneira como as minorias sexuais e de gênero são discriminadas, a partir do padrão cis-heteronormativo, parte do processo democrático. Rodrigues (2010) continua sua contribuição para este estudo, ao afirmar que

O exercício democrático é um processo duro, penoso, paradoxal, que, às vezes, não nos deixa dormir. O exercício da democracia não é um passeio em jardins do paraíso. Mas, mesmo quando forças sociais obtêm vitórias na afirmação de seus valores reacionários, continuamos em um processo democrático, se ainda podemos fazer interferência discursiva, podemos problematizar a sociedade e a vida. (p.20)

É nesse sentido que a população LGBTI no Brasil tem construído sua trajetória na luta pela efetivação da cidadania, determinada pela $\mathrm{CF} / 88$, principalmente pelo seu artigo $5^{\circ}$, que iguala todos os indivíduos em termos de direitos (Brasil, 1988). É um processo em constante construção, que ganhou força no final da década de 70, durante a ditadura militar brasileira, como uma forma de resposta às opressões vividas na época (Costa, 2015; Santos, 2018a). O movimento, iniciado no final da década de 70 durante a ditadura, ficou conhecido como Movimento Homossexual Brasileiro (MHB). Em 1980, aconteceu $01^{\circ}$ Encontro Brasileiros de Homossexuais (EBHO) como um pontapé inicial 
no movimento, que tinha o intuito de unir as pessoas homossexuais e mobilizar para a despatologização da homossexualidade, que aconteceu em 1985 (Kauss \& Albernaz, 2015; Reis, 2018), momento que a mobilização havia perdido forças devido a redemocratização do país e a epidemia da AIDS33. Ainda nesse momento, houve a troca do uso do termo "opção sexual" para "orientação sexual" retirando a possibilidade de interpretação de que a sexualidade seja uma escolha (Costa, 2015). A partir da década de 9o, começa-se a discutir sobre a criação de um órgão que representasse a população LGBT. No $4^{\circ}$ Encontro Brasileiro de Homossexuais (EBHO), em 1990, levantou-se o possível nome: "Conselho Brasileiro de Entidades Organizadas Homossexuais". Nesse mesmo momento, iniciou-se a candidatura política de integrantes do movimento (Costa, 2015; Reis, 2018).

Pouco depois, inicia-se uma discussão acerca do machismo e sexismo presentes no movimento, até então tomado como GLB, algo que indicava uma invisibilização das lésbicas, transexuais e travestis (Kauss \& Albernaz, 2015). Assim, no $6^{\circ}$ Encontro Brasileiro de Homossexuais (EBHO), lésbicas reivindicaram maior espaço no movimento, colocando as questões sexistas em pauta, fazendo com que o $7^{\circ} \mathrm{EBHO}$ se tornasse o EBLHO, inserindo a letra " $L$ " na frente da palavra homossexual4. A letra " $T$ ", de transexuais e travestis, só foi inserida no encontro em 1997 - $9^{\circ}$ EBLGT. Nos encontros ocorridos nesse período, aconteceram as discussões sobre a proposição de leis a respeito da discriminação por orientação sexual e do Contrato Civil. ${ }^{5}$ Além disso, houve a criação da Associação Brasileira de Gays, Lésbicas e Travestis (ABGLT) em 1995 e de uma passeata pela cidade de Curitiba (PR), que culminou na criação das Paradas LGBTI em 1997 (Reis, 2018).

A partir dos anos 2000, ganha força a preocupação sobre as proposições governamentais com relação à garantia de direitos previstos em Constituição, tais como: Conselho Nacional de Combate à Discriminação (CNCD) em 2001, a criação do Programa Nacional de Direitos Humanos (PNDH II) em 2002, a Frente Parlamentar Mista pela Livre Expressão Sexual em 2003 (Costa, 2015; Santos, 2018a). Em 2004, criase o Programa Brasil sem Homofobia, através do Conselho Nacional de Combate à Discriminação. Em 2008, tem-se o fim dos EBLHO, pois iniciaram as Conferências Nacionais de Direitos Humanos da População LGBT, que está na sua terceira edição (Costa, 2015; Reis, 2018). Em 2009, lança-se o PNDH III, que propunha o combate às

\footnotetext{
3 Epidemia da AIDS causou uma divisão do movimento. Alguns buscavam respostas do Estado para o combate à AIDS e outros lutavam para o afastamento da imagem negativa do "aidético" (Costa, 2015).

4 Lésbicas são mulheres homossexuais, mas acabou-se criando essa diferenciação que ainda está enraizada no senso comum ao vincular homossexual apenas para homens gays.

5 Poder Judiciário, por sua vez, através de suas prerrogativas constitucionais, publicou decisões e atos normativos que acabaram por garantir maior cidadania à população LGBTI, como a resolução $\mathrm{n}^{\circ}{ }^{175} \mathrm{de}$ 2013 reconhecendo a união estável homoafetiva e a criminalização da LGBTfobia através do enquadramento de atos de homofobia e transfobia à Lei n ${ }^{\circ} 7.716 / 1989$ que se refere à práticas racistas (Conselho Nacional de Justiça, 2013; Supremo Tribunal Federal, 2019).
} 
desigualdades e o respeito à diversidade. Essas são algumas ações estatais em prol dos direitos das pessoas LGBTI. Tais conquistas vieram das lutas sociais, principalmente do movimento LGBT no Brasil. Entretanto, esses direitos são compreendidos como "direitos sexuais", embora as exigências de equiparação de direitos não têm, muitas vezes, a ver com a sexualidade pois, tratam questões como, adoção, previdência, casamento, segurança etc. Ou seja, "conforme construídos contemporaneamente no Brasil, os direitos sexuais referem-se às prerrogativas legais relativas ou à sexualidade ou a grupos sociais cujas identidades foram forjadas sobre formas específicas de desejos e de práticas sexuais" (Carrara, 2012, p. 135).

Apesar dessa consideração, a partir do Programa Brasil sem Homofobia, criou-se o Projeto Escola sem Homofobia que tem como objetivo criar ações que promovam os Direitos Humanos e o respeito às pessoas LGBTI nas escolas de Ensino Básico. A proposta era acontecer através de formações de professores para que estivessem preparados caso ocorressem discussões relacionadas ao gênero e a sexualidade (Vianna, 2018). Porém, o projeto sofreu retaliações da bancada religiosa e da mídia brasileira, sendo assim vetado pela Presidente da República em 2011, mesmo com o amparo de dados representativos com relação à discriminação de jovens LGBTI nas escolas (Kauss \& Albernaz, 2015; Vianna, 2018). Outra ação semelhante foi a retirada das menções de gênero no Plano Nacional de Educação em 2014 (Vianna, 2018). A dificuldade de se efetivar políticas que discutam as questões relativas aos direitos das minorias sexuais e de gênero são pontos que continuam precisando de atenção e ação.

Entretanto, mesmo com os revezes sofridos pelas minorias sexuais e de gênero no percurso da conquista de direitos, a trajetória do movimento teve um avanço quando iniciaram as conferências e congressos: as pautas ganharam visibilidade e complexidade (Santos, 2018b). E, nesse percurso, os grupos LGBTI precisaram alinharse ao discurso de uma igualdade, uma lógica mais dentro de "uma perspectiva de homogeneização do que de uma luta pelo direito à diferença". Ou seja, mesmo de forma contraditória, foi preciso que o movimento social LGBTI se estruturasse a partir de uma estratégia de um certo apaziguamento e se encaixasse na norma para conquistar o apoio do governo para financiamento e aprovação dos projetos sociais (Lima, 2017, p. 94).

Essa estratégia do movimento LGBTI pode ser alinhada ao conceito de um estilo de comportamento nomeado por Moscovici (2011) de "equidade", que "expressa a preocupação de levar em conta a postura dos outros" (p. 148). O autor pontua que esse estilo de comportamento demonstra manter a sua consistência e, ao considerar a visão da maioria, permite que a minoria se torne mais aceitável e, dessa forma, mais suscetível à influência. Não há indicação de qual seja o melhor tipo de comportamento que a minoria deva adotar em busca de uma transformação social, porém, nota-se na trajetória dos movimentos sociais LGBTI no Brasil, que essa foi uma estratégia possível para conseguir o apoio do Estado na possibilidade de angariar acesso aos direitos. 


\section{Minorias e escola}

A instituição escolar não é um espaço isolado do mundo, que apenas constrói e transmite conhecimento, ela está bem longe dessa concepção, assim como na sociedade, reproduz desigualdades. A Escola, instituição integrada à sociedade e reprodutora das forças hegemônicas é campo de disputa política na qual grupos majoritários buscam afirmar suas ideologias por meio de políticas educacionais que legitimam o sistema hegemônico. A escola, por meio dos currículos e práticas pedagógicas, faz com que, ao mesmo tempo em que tenha a função social de trabalhar a diversidade e diferenças, seja instrumento de controle social por meio desses mesmos aparatos (Sacristán, 2000).

A homogeneização da instituição e dos sujeitos presente no ambiente escolar coloca todos apenas como alunos, ignorando sua idade, sexo, cor da pele, posição social e vivências, classificando-os como bons ou maus. Dessa forma, os sentidos atribuídos à escola pelos sujeitos são ignorados e o ambiente torna-se uma forma de reprodução de ideias liberais, que acabam por transformar o conhecimento em um produto (Dayrell, 2001).

É preciso notar que, ao construir e trocar conhecimento, a escola também "fabrica" sujeitos e subjetividade(s). As práticas para se naturalizar a ordem hegemônica, juntamente com a formação dos sujeitos para reproduzir papéis sociais préestabelecidos, incorrem por meio de diferentes símbolos e práticas escolares. Louro (2007), ao refletir sobre as diferenças e desigualdades reproduzidas na escola, aponta:

A escola entende disso. Na verdade, a escola produz isso. Desde seus inícios, a instituição escolar exerceu uma ação distintiva. Ela se incumbiu de separar os sujeitos - tornando aqueles que nela entravam distintos dos outros, os que a ela não tinham acesso. (Louro, 2007, p. 57)

Assim, a escola é produtora e reprodutora da lógica hegemônica das maiorias sociais, mas, por outro lado, a escola é o lugar em que diferentes pessoas e modos de vida coexistem, e, por isso, também é lugar de existência e resistência das minorias sexuais e de gênero. O movimento de resistência dessas minorias dentro do ambiente escolar deve ser considerado para se pensar em novas estratégias políticas e em visibilidade.

Entendendo a relação das minorias sexuais e de gênero com a educação, é preciso incutir um pensar em direção à educação democrática, nos moldes trazidos pelas contribuições de Paulo Freire, que insere a importância da criticidade dos seres que estão em formação, para que estes consigam se envolver de maneira ativa nas problemáticas que vivenciam, e nesse sentido, participem ativamente, em resistência às violências vivenciadas com relação à sua sexualidade ou sua identidade de gênero (Freire, 1967; Hooks, 2013). A educação crítica, compreendendo a lógica hegemônica 
de reprodução constante de uma cisheteronormatividade branca, a qual está inserida, possibilita a discussão e movimentação para uma não naturalidade da pedagogia da sexualidade, de que meninos transitam apenas pelo universo dado ao "masculino" e meninas pelo universo "feminino", fazendo uma separação dos banheiros, brincadeiras, uniformes, cores, esportes e currículo (Nunes, 2019).

Apesar de o Brasil vivenciar um discurso de "pluralismo cultural" e "democracia racial" e haver discursos insistentes sobre ser um país diverso, as identidades que não são cisgênero, branco e heterossexual, são marcadas e definidas como "outras", fora do "normal". Nas escolas, os espaços, as disciplinas e atividades são construídas a partir do padrão e quem não se encaixa vivencia as marcações de ser "outro" através das violências cotidianas (Louro, 2000). As marcações deste "outro" são referenciadas através do corpo, das expressões de gênero no meio social. O corpo fornece elementos para um julgamento imediato de quais identidades o sujeito estabelece. Ou seja, "espera-se que o corpo dite a identidade de forma que seu julgamento seja feito sem quaisquer ambiguidades e nem mesmo inconstância" (Nascimento \& Cruz, 2018, p. 24), sendo estigmatizadas, marcadas, invisibilizadas e excluídas as identidades que não são adequadas dentro da heteronormatividade.

Na escola, existem tensões sob a cisheterornormatividade. Ao mesmo tempo em que existem movimentos que reforçam a norma, existem movimentos que a subvertem, na tentativa de naturalizar todas as expressões de gênero e de sexualidade, que, através de sujeitos LGBTI, se expressam de forma a explicitar sua identidade, rompendo com a norma hegemônica (Nascimento \& Cruz, 2018). Assim, as minorias LGBTI, através de suas ações subjetivas ou objetivas, são capazes de externalizar suas ideologias e exercer influência. É possível que as mudanças, no que se refere à Educação e a escola, aconteceram por conta de minorias ativas que reivindicaram seus direitos e foram capazes de modificar alguns pensamentos de parte da sociedade, ou pelo menos de fazer refletir sobre eles.

Ainda nesse sentido, mesmo havendo projetos políticos pró minorias sexuais e de gênero no Brasil, existem dificuldades na sua aprovação e execução. Como mencionado anteriormente, existe um trabalho no sentido de regular a prática profissional de docentes através de leis e currículos. Porém, ainda há a preservação de uma certa autonomia das professoras e professores que podem atuar de forma a contribuir para a noção cisheteronormativa ou agir de maneira contrária a ela. A atuação dependerá da forma como a e o docente se relaciona com a diversidade (Araújo, 2015). Quando há negação da discussão da temática, automaticamente nega-se a existência de pessoas LGBTI e nega-se as violências vivenciadas por este grupo que muitas vezes acarreta a expulsão do sujeito do espaço escolar pelo sistema heteronormativo. Dessa forma, agem em cumplicidade com o preconceito (Araújo, 2015). Em contrapartida, as formações de docentes fornecem um suporte interessante para a mudança do posicionamento frente à temática. Abrem uma possibilidade para um processo 
dialógico em que docentes comecem a aproveitar situações no cotidiano escolar para construir diálogos sobre as sexualidades e os gêneros, problematizando a cisheteronormatividade (Araújo, 2015; Madureira \& Branco, 2015; Soares \& Monteiro, 2019).

Entretanto, é preciso refletir que a problemática trazida pela cisheteronormatividade tem efeitos na sociedade como um todo e pensar em formações de professores é apenas um movimento, básico, para começar a pensar a discussão em termos práticos dentro do ambiente escolar. Porém, os estudos de gênero e os movimentos sociais promovem transformações nos conhecimentos estruturados ao longo do tempo e abrem possibilidades para novos entendimentos, não somente para educação, mas para todos os direitos humanos. Ou seja, pensa-se em novas formas de arte, novos aparecimentos de pessoas LGBTI em espaços como a política e a mídia, reestruturando, assim, novas formas de ser e estar no mundo (Araújo, 2015; Louro, 2011).

\section{Considerações finais}

As minorias sexuais e de gênero enfrentaram e ainda enfrentam diferentes desafios para serem reconhecidas e respeitadas e para exercerem seus direitos como cidadãos e cidadãs dentro de uma sociedade que deveria ser democrática. Conforme vimos, dentre esses desafios está o de entrar e manter-se na Escola, de ter direito à Educação. A Escola, por sua vez, encara o desafio de ser de fato democrática e não reproduzir as desigualdades e injustiças sociais. Neste trabalho buscamos relatar tais dificuldades e apontar reflexões para uma educação democrática para as minorias sexuais e de gênero.

O desprezo do atual governo brasileiro em relação às minorias sexuais e de gênero é um fator que dificulta os caminhos para uma escola democrática. O crescente conservadorismo, presente nas bancadas evangélicas do poder legislativo brasileiro, distorcem a discussão sobre a importância da abordagem do tema sobre diversidade sexual e de gênero no âmbito da Educação como ferramenta de combate a discriminação.

A partir da análise feita sobre as minorias sexuais e uma Educação democrática, verifica-se que houve avanços significativos nos direitos das minorias a partir de suas lutas e pautas. É possível perceber que as minorias sexuais e de gênero possuem influência sobre a sociedade, e essa é necessária para a transformação social. Quando uma minoria se confronta com uma maioria essa é capaz de exercer influência sobre a maioria trazendo suas reivindicações para o centro das discussões políticas, culturais e sociais.

A Escola, como reflexo da sociedade, carrega em sua história a reprodução de normas hegemônicas, que são confrontadas quando minorias sexuais e de gênero 
rompem a barreira do silêncio ou do ocultamento reproduzido no ambiente escolar. Para romper essas regras, as minorias colocam-se de maneira a apresentar sua subjetividade aos demais e mostram que suas ideias não devem necessariamente seguir o padrão adotado pela maioria. A individualidade é colocada para a sociedade evidenciando que existem outras maneiras de ser e estar no mundo que diferem da maioria. Mas, para isso, é necessário romper com a realidade objetiva, usar desta última como base para apresentar suas crenças e até mesmo elaborá-las. Isso pode resultar na cessão às normas da maioria ou adequação das exigências hegemônicas.

Conforme visto ao longo do texto, o Brasil, por meio de sua legislação, traz bases para que as minorias sexuais e de gênero sejam incluídas e respeitadas dentro do ambiente escolar, pautadas, na maioria das vezes, pela discussão acerca da diversidade sexual e de gênero. Contudo, acredita-se que trabalhar essas questões por si só não necessariamente faz com a escola seja democrática, para além da inclusão dos temas na escola é necessário que se estabeleçam políticas públicas de Educação e práticas pedagógicas no interior da escola que sejam antinormativas, ou seja, que quebrem com a lógica hegemônica das maiorias em vez de simplesmente acrescentar outros modos de vida e de mundo dentro de suas temáticas. Pois é justamente a lógica hegemônica que transforma diferenças em desigualdades.

Verificando tudo que foi exposto, nota-se a necessidade de subsídios e políticas públicas que consideram a diversidade de gênero e de identidade e também a formação de professores, partindo do pressuposto de que apenas os documentos norteadores e as vivências profissionais não têm sido suficientes para a desconstrução de práticas educacionais cisheterocentradas.

Para pesquisas futuras, há possibilidade de novas análises acerca das pautas e lutas dos diferentes subgrupos que compõem as minorias sexuais e de gênero, já que ainda há necessidade de dar visibilidade para grupos ainda mais minoritários dentro da sigla LGBTI e que apresentam ainda mais vulnerabilidades. Um outro estudo pertinente seria a investigação sobre os tipos de influência exercidos pelas minorias sexuais e de gênero sobre as maiorias no ambiente escolar, dentro do campo de estudo da psicologia social. Isso incidiria em outros estudos, também centrados na reflexão sobre as características antidemocráticas da escola por meio de práticas cisheterocentradas, para compreender as lutas e pensar em propostas voltadas para a população LGBTI no Brasil e, quiçá, no mundo.

\section{Referências}

Associação Brasileira de Gays, Lésbicas, Bissexuais, Travestis, Transexuais e Intersexos (2016).Pesquisa Nacional Sobre o Ambiente Educacional no Brasil. Obtido em: https://static.congressoemfoco.vol.com.br/2016/08/IAE-Brasil-Web-3-1.pdf 
Araújo, D. B. De. (2015). Outras falas sobre gênero e sexualidade na escola. Revista Periódicus, Obtido 1-9. em: https://doi.org/http://dx.doi.org/10.9771/peri.v1i2.1287

Antunes, F., \& Peroni, V. (2017). Reformas do Estado e políticas públicas: trajetórias de democratização e privatização em educação. Brasil e Portugal, um diálogo entre pesquisas. Revista Portuguesa de Educação, 30(1), 181-193. doi:10.21814/rpe.7399.

Bento, B. (2017). Tranviad@s: gênero, sexualidade e direitos Humanos. Salvador: EDUFBA. Obtido em: https://repositorio.ufba.br/ri/handle/ri/26037.

Blais, M., Philibert, M., \& Chamberland, L. (2018). Literature Revier Report on the indicators of inclusion and exclusion of $L G B T Q+$ people. Understanding Inclusion and Exclusion of LGBTQ people Research Partnership (UNIE-LGBTQ). Montréal: Université du Québecéal. Obtido de: https://savie-Igbtq.uqam.ca/wpcontent/uploads/2018/07/Rapport_Recension_ENG_FINAL_Print.pdf.

Bortoni, L. (2018). Brasil é o país onde mais se assassina homossexuais no mundo. Obtido em: $\quad$ https://www12.senado.leg.br/radio/1/noticia/brasil-e-o-pais-que-maismata-homossexuais-no-mundo.

Brasil. (1988). Constituição da República Federativa do Brasil: promulgada em 5 de outubro de 1988. Brasília: Senado Federal. Obtido em: http://www.planalto.gov.br/ccivil_03/constituicao/constituicaocompilado.htm.

Brasil. (1999). Parâmetros curriculares nacionais/ensino fundamental: orientação sexual. Brasília: Ministério da Educação. Obtido em: http://portal.mec.gov.br/seb/arquivos/pdf/livro102.pdf.

Chaves, L.G. Mendes. Minorias e seus estudos no Brasil. Revista de Ciências Sociais, Fortaleza, v.2., n.1, p. 149-168, $1971 . \quad$ Obtido em:file:///C:/Users/estev/Downloads/42512-Texto\%20do\%20artigo-140426-110-20191122\%20(2).pdf . Acesso em: 20/07/2020

Carrara, S. (2012). Políticas e Direitos Sexuais no Brasil Contemporâneo. Bagoas Estudos Gays: Gêneros e Sexualidades, 4(05). Obtido em: https://www.cchla.ufrn.br/bagoas/v04no5arto8_carrara.pdf

Conselho Nacional de Justiça. (2013). Resolução 175 de 2013. Obtido em: https://atos.cnj.jus.br/atos/detalhar/1754

Costa, L. P. (2015). O judiciário enquanto aliado do movimento LGBT: perspectivas positivas e negativas em comparação ao legislativo na busca pela criminalização da homofobia. In Universidade Federal do Rio Grande do Sul. Obtido em: https://doi.org/10.1377/h/thaff.2013.0625

Dayrell, J. A escola como espaço sócio-cultural. In: Dayrell, J. (Org.) Múltiplos olhares sobre educação e cultura. Belo Horizonte: Editora UFMG, 2001, p. 136-161. Obtido

em: 
http://www.scielo.br/scielo.php?script=sci_nlinks\&ref=000119\&pid=S0102469 $8201200020001300012 \&$ lng $=$ pt.

Freire, P. (2019). Educação como prática da liberdade.45a ed. São Paulo, Brasil: Paz e Terra.

Gentili, P. (1996). Neoliberalismo e educação: manual do usuário. In Escola, S.A. Quem ganha e quem perde no mercado educacional do neoliberalismo. Obtido em: https://barricadasabremcaminhos.files.wordpress.com/2010/06/neoliberalismo -e-educacao.pdf.

Hooks, B. (2013). Ensinando a transgredir: a educação como prática de liberdade. São Paulo, Brasil: Editora WMF Martins Fontes.

Igartua, K. J., \& Montoro, R. (2015). Les minorités sexuelles: Concepts, prémisses et structure d'une approche clinique adaptée. Sante Mentale Au Quebec, 40(3), 19-35. Obtido em: https://doi.org/10.7202/1034909ar

Kauss, B. S., \& Albernaz, R. O. (2015). Do movimento social LGBT brasileiro ao projeto de lei n. 122/2006 e o estatuto da diversidade sexual. Revista da Ajuris, 42(139), 29-49. Obtido em: http://ajuris.kinghost.net/OJS2/index.php/REVAJURIS/article/view/529

Lima, A. M. (2017). Política sexual: os direitos humanos $L G B T$ entre o universal e o particular. Belo Horizonte, Brasil: Relicário Edições.

Louro, G. L. (2011). Educação e docência: diversidade, gênero e sexualidade. Formação Docente, 3(4), 62-70. Obtido em: https://www.revformacaodocente.com.br/index.php/rbpfp/article/view/31

Louro, G. L. (2000). Corpo, escola e identidade. Educação e Realidade, 25(2), 59-75. Obtido em: https://seer.ufrgs.br/educacaoerealidade/article/view/46833.

Louro, G. L. (2007). Gênero, sexualidade e educação. Educação em Revista, 46(1), 201218. Obtido em: https://www.scielo.br/pdf/edur/n46/ao8n46.pdf.

Louro, G. L. (2008). Gênero e sexualidade: pedagogias contemporâneas. Pro-posições, 19(2), 17-23. Obtido em: http://www.scielo.br/scielo.php?script=sci_arttext\&pid=S0103$73072008000200003 \& \operatorname{lng}=e n \& n r m=i s o$.

Mbembe, A. (2006). Necropolítica: Biopoder, soberania, estado de exceção, política de

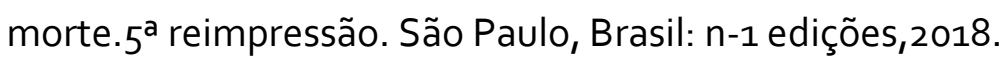

Madureira, A. F. do A., \& Branco, Â. U. (2015). Gênero, sexualidade e diversidade na escola a partir da perspectiva de professores/as. Temas em Psicologia, 23(3), 577-591. Obtido em: https://doi.org/10.9788/TP2015.3-05

Monroe, C. (2011). O acesso à escola melhorou: o desafio, agora, é a qualidade. Obtido em: https://novaescola.org.br/conteudo/2765/o-acesso-a-escola-melhorou-odesafio-agora-e-a-qualidade.

Moscovici, S. (2011). Psicologia das minorias ativas. Rio de janeiro, Brasil: Vozes. 
Nascimento, A. P. L., \& Cruz, M. H. S. (2018). Gênero, sexualidades e juventudes: regulações e subversões dos corpos no cotidiano escolar. Cadernos de Gênero e Diversidade, 4(3), 14-28. Obtido em: https://doi.org/10.9771/cgd.v4i3.25591

Nunes, H. B. (2019). "Aqui na escola é bom porque tem gente de tudo que é tipo: as sapata, os viado, as bixa!": narrativas ficcionais sobre existir e resistir no espaço- tempo recreio a partir de uma perspectiva feminista decolonial dos saberes (Dissertação em Educação). Universidade do Rio Grande do Sul, Porto Alegre, Brasil. Obtido em: http://hdl.handle.net/10183/202064.

Brasil (1999) Parâmetros Curriculares Nacionais/ Ensino Fundamental: Orientação sexual. Brasília, Brasil: Ministério da Educação.

Reis, T. (2018). OS EBGLTs. In Marcio, C., \& Rodrigues, A. Quando ousamos existir: itinerários fotobiográficos do movimento LGBTI brasileiro (1978-2018). Tubarão: Copiart. Obtido em: http://memorialgbti.org/wpcontent/uploads/2019/01/QUANDO-OUSAMOS-EXISTIR_Interativo.pdf.

Rodrigues, H. J. A. (2010). Pensando minorias sexuais e de gênero sob a perspectiva das Políticas Públicas e de subjetivação. Obtido em: http://repositorio.ufes.br/bitstream/10/2883/1/tese 4275.pdf

Sacristán, José Gimeno. (2000). O currículo: uma reflexão sobre a prática. 3. ed. Porto Alegre, Brasil: Artmed.

Santos, E. (2018a). A agenda LGBTI no Congresso Nacional: de João A. Mascarenhas à Jean Wyllys. In Marcio, C., \& Rodrigues, A. Quando ousamos existir: itinerários fotobiográficos do Movimento LGBTI brasileiro (1978-2018). Tubarão: Copiart. Obtido em: http://memorialgbti.org/wp-content/uploads/2019/01/quandoousamos-existir_Interativo.pdf

Santos, L. F. S. (2018b). História do movimento LGBT brasileiro : interpretações sobre as dinâmicas da interação entre o movimento social e o estado. Obtido em: http://repositorio.ufla.br/jspui/handle/1/39422.

Soares, Z. P., \& Monteiro, S. S. (2019). Formação de professores/as em gênero e sexualidade: possibilidades e desafios. Educar Em Revista, 35(73), 287-305. Obtido em: https://doi.org/10.1590/0104-4060.61432

Sodré, M. (2005). Por um conceito de minoria. In Comunicação e cultura das minorias (pp. 1-2). Obtido em: https://pt.scribd.com/document/59696720/SODREMuniz-Por-Um-Conceito-de-Minoria

Supremo Tribunal Federal. (2019). STF enquadra homofobia e transfobia como crimes de racismo ao reconhecer omissão legislativa. Obtido em: http://www.stf.jus.br/portal/cms/verNoticiaDetalhe.asp?idConteudo=414010]

Todos pela Educação. (2018). Quatro em cada 1o jovens de 19 anos ainda não concluíram o Ensino Médio. Obtido em: https://www.todospelaeducacao.org.br/conteudo/quatro-em-cada-10-jovens- 
de-19-anos-ainda-nao-concluiram-o-ensino-medio.

Vianna, C. (2018). Políticas de Educação, gênero e diversidade sexual: breve história de lutas, danos e resistências. Belo Horizonte, Brasil: Autêntica.

\section{Cómo referenciar este artículo/How to reference this article(*):}

Paulo Ribeiro, L., Esteves da Costa, M., y Campos Freitas D'Avila, I. (2021). Minorías sexuales, de género y educación: demandas y luchas LGBTI en el contexto brasileño. iQUAL. Revista de Género e lgualdad, 4 , 124-141, doi: 10.6018/iqual.440901

Paulo Ribeiro, L., Esteves da Costa, M., y Campos Freitas D'Avila, I. (2021). Minorías sexuales, de género y educación: demandas y luchas LGBTI en el contexto brasileño. [Sexual, gender and education minorities: LGBTI demands and struggles in the Brazilian context]. iQUAL. Revista de Género e lgualdad, 4, 124-141, doi: 10.6018/iqual.440901

(*) La autoría colectiva responde a una contribución conjunta en todos los apartados. 